American Journal of Microbiology 2 (2): 25-34, 2011

ISSN 1948-982x

(C) 2011 Science Publications

\title{
Bacteria on Human Skin
}

\author{
${ }^{1,3}$ Richard W. Hyman, ${ }^{1,3}$ Farbod Babrzadeh, \\ ${ }^{1,3}$ Curtis Palm, ${ }^{1,3}$ Chunlin Wang, ${ }^{3}$ Marilyn Fukushima and ${ }^{1,2,3}$ Ronald W. Davis \\ ${ }^{1}$ Departments of Biochemistry, \\ ${ }^{2}$ Departments of Genetics, \\ ${ }^{3}$ Stanford Genome Technology Center, \\ Stanford University, 855 S. California Ave. Palo Alto, 94304, CA
}

\begin{abstract}
Problem statement: Human skin is a large $\left(\sim 1.75 \mathrm{~m}^{2}\right)$ organ containing a large number of ecologically distinct sites. These sites harbor a variety of distinct microbiomes. One challenge is to define the microbiome at every site. We chose two interesting sites: the base of the Front of the neck and the base of the Back of the neck (the nape) and enrolled forty volunteers. These two sites are interesting because the bacteria therein must interact with the skin and its microbiome and with clothing and hair and the external environment. Approach: The volunteers took their own neck swabs. Total DNA was prepared from each swab. That DNA was employed as a template in separate PCR reactions to amplify the V6 and V3 regions of the 16S ribosomal RNA gene. The V6 and V3 regions were pyrosequenced using Roche 454 Life Sciences technology. To identify the bacteria, the sequences were compared to the data in the Ribosomal Database Project. Results: From the sequences of the V6 region, it was found that all of the swabs contained at least $1 \%$ of the reads as Actinobacteria and Gammaproteobacteria. The substantial majority of the swabs contained at least $1 \%$ of the reads as Alphaproteobacteria, Bacilli and Betaproteobacteria. About half of the swabs contained at least $1 \%$ of the reads as Flavobacteria and Sphingobacteria. A few swabs contained Clostridia or Cyanobacteria at least at the $1 \%$ level. The Class of Gammaproteobacteria was supported by the most reads for $94 \%$ of the swabs. Conclusion: As a measure of bacterial diversity, the Shannon Diversity Index was computed from the V6 data for each swab and considered as a function of the number of reads. The Front and Back curves were indistinguishable. To determine how close the data were to saturation, the Chaol curves for the Front and Back swabs were constructed. The two curves were indistinguishable. Neither curve appeared close to saturation.
\end{abstract}

Key words: Skin microbes, human microbiome

\section{INTRODUCTION}

Adult human skin is a large organ $\left(\sim 1.75 \mathrm{~m}^{2}\right)$ with many important functions (Percival et al., 2011). The skin is composed of very many distinguishable ecological niches. Each niche could harbor its own distinct microbiome, which may depend, at least in part, on clothing and personal hygiene. These may change with the seasons. Therefore, a complete description of the adult human skin microbiome, in health and in disease, may require following very many skin sites on very many people as a function of time. An excellent start has been made in defining the human skin microbiome (for recent reviews, see Grice and Segre, 2011; Kong, 2011).

Given the limits on time and money that exist in the real world, there is a choice between investigating many sites on a few people (e.g., twenty sites on ten people; Grice et al., 2009) or a few sites on many people (e.g., two sites on fifty-one people; Fierer et al., 2008). We have opted for the latter and identified the skin microbiome at two sites: the base of the Front of the neck and the base of the Back of the neck (the nape) on forty volunteers. These two sites are interesting because the bacteria therein must interact with the skin and its microbiome and with clothing and hair and the external environment.

\section{MATERIALS AND METHODS}

Human subjects: The Stanford University Institutional Review Board approved this study of skin microbes. In total, forty volunteers were recruited (Table 1). All forty gave written informed consent. The volunteers ranged in age from 19-85 years. Those volunteers who took antibiotics at any time during the previous three months or had a significant underlying medical condition were ineligible to volunteer for this study.

Corresponding Author: Richard W. Hyman, Stanford Genome Technology Center, Stanford University, 855 S. California Avenue, Palo Alto, 94304, CA Tel: 650-812-1972 Fax: 650-812-1975 
Am. J. Microbiology 2 (2): 25-34, 2011

\begin{tabular}{|c|c|c|c|c|c|c|c|c|c|c|c|}
\hline Volunteer & $\mathrm{M} / \mathrm{F}^{\mathrm{a}}$ & $\begin{array}{l}\text { Long hair } \\
\text { (back) }\end{array}$ & $\begin{array}{l}\text { V6 SDI } \\
\text { F/B }{ }^{\mathrm{c}}\end{array}$ & $\begin{array}{l}\text { V6 SDI } \\
\text { (Class) }^{\mathrm{d}}\end{array}$ & (Order) & Volunteer & $\mathrm{M} / \mathrm{F}^{\mathrm{a}}$ & $\begin{array}{l}\text { Long hair } \\
\text { (back) }\end{array}$ & $\begin{array}{l}\text { V6 SDI } \\
\text { F/B }{ }^{c}\end{array}$ & $\begin{array}{l}\text { V6 SDI } \\
\text { (Class) }^{\mathrm{d}}\end{array}$ & (Order) \\
\hline \multirow[t]{2}{*}{1} & $\mathrm{M}$ & & F & 2.48 & & 22 & $\mathrm{M}$ & & F & 2.18 & \\
\hline & & & B & 2.73 & & & & & B & 1.79 & \\
\hline \multirow[t]{2}{*}{2} & M & & F & 2.19 & & 23 & F & & F & 2.61 & \\
\hline & & & B & 2.28 & 2.48 & & & $\mathrm{Y}$ & B & 1.91 & 2.14 \\
\hline \multirow[t]{2}{*}{3} & M & & F & 2.66 & & 24 & M & & F & 2.32 & \\
\hline & & & B & 2.36 & 2.45 & & & & B & 2.04 & \\
\hline \multirow[t]{2}{*}{5} & M & & F & 2.32 & 2.50 & 25 & M & & F & 1.84 & \\
\hline & & & B & 2.18 & & & & & B & 1.68 & 2.58 \\
\hline \multirow[t]{2}{*}{6} & M & & $\mathrm{F}$ & 2.37 & & 26 & F & & F & 1.82 & \\
\hline & & & B & 2.60 & & & & & B & 2.01 & \\
\hline \multirow[t]{2}{*}{7} & F & & $\mathrm{F}$ & 2.14 & 2.39 & 27 & M & & $\mathrm{F}$ & 1.55 & 2.47 \\
\hline & & $\mathrm{Y}^{\mathrm{b}}$ & B & 1.90 & 2.22 & & & & B & 1.55 & 2.14 \\
\hline \multirow[t]{2}{*}{8} & F & & $\mathrm{F}$ & 2.76 & & 28 & M & & $\mathrm{F}$ & 2.01 & \\
\hline & & Y & B & 2.70 & & & & & B & 2.47 & 2.47 \\
\hline \multirow[t]{2}{*}{9} & F & & $\mathrm{F}$ & 2.23 & & 29 & F & & $\mathrm{F}$ & 1.79 & \\
\hline & & Y & B & 2.39 & & & & $\mathrm{Y}$ & B & 2.24 & 2.16 \\
\hline \multirow[t]{2}{*}{10} & F & & $\mathrm{F}$ & 2.69 & & 30 & M & & $\mathrm{F}$ & 1.74 & 2.83 \\
\hline & & $\mathrm{Y}$ & B & 2.20 & & & & & B & 2.07 & 2.5 \\
\hline \multirow[t]{2}{*}{11} & F & & $\mathrm{F}$ & 3.09 & & 31 & M & & $\mathrm{F}$ & 1.95 & \\
\hline & & $\mathrm{Y}$ & B & 1.56 & & & & & B & 1.84 & \\
\hline \multirow[t]{2}{*}{12} & M & & $\mathrm{F}$ & 1.99 & & 32 & M & & $\mathrm{F}$ & 1.76 & \\
\hline & & & B & 2.76 & & & & & B & 2.15 & \\
\hline \multirow[t]{2}{*}{13} & M & & $\mathrm{F}$ & 2.38 & & 33 & F & & $\mathrm{F}$ & 2.58 & \\
\hline & & & B & 2.00 & & & & Y & B & 2.65 & \\
\hline \multirow[t]{2}{*}{14} & M & & $\mathrm{F}$ & 2.68 & & 34 & M & & $\mathrm{F}$ & 2.31 & \\
\hline & & & B & 2.32 & & & & & B & 2.08 & 2.19 \\
\hline \multirow{2}{*}{15} & M & & $\mathrm{F}$ & 1.58 & 2.20 & 35 & M & & $\mathrm{F}$ & 1.63 & 2.66 \\
\hline & & & B & 1.69 & 2.36 & & & & B & 1.19 & 2.07 \\
\hline \multirow[t]{2}{*}{16} & M & & $\mathrm{F}$ & 2.17 & & 36 & F & & $\mathrm{F}$ & 2.07 & \\
\hline & & & B & 1.87 & 2.28 & & & & B & 1.46 & 2.01 \\
\hline \multirow[t]{2}{*}{17} & M & & $\mathrm{F}$ & 2.40 & 2.77 & 37 & M & & $\mathrm{F}$ & 1.84 & \\
\hline & & & B & 2.68 & & & & & B & 1.44 & 2.12 \\
\hline \multirow[t]{2}{*}{18} & $\mathrm{M}$ & & $\mathrm{F}$ & 2.06 & & 38 & M & & $\mathrm{F}$ & 2.01 & \\
\hline & & & B & 2.14 & & & & & B & 1.81 & 2.19 \\
\hline \multirow[t]{2}{*}{19} & $\mathrm{M}$ & & $\mathrm{F}$ & 2.21 & 2.40 & 39 & M & & $\mathrm{F}$ & 2.58 & \\
\hline & & $\mathrm{Y} / \mathrm{N}$ & B & 1.90 & 2.62 & & & & B & 1.90 & 2.62 \\
\hline \multirow[t]{2}{*}{20} & F & & $\mathrm{F}$ & 2.57 & & 40 & F & & $\mathrm{F}$ & 2.24 & \\
\hline & & $\mathrm{Y}$ & B & N/A & & & & $\mathrm{Y}$ & B & 1.43 & 1.87 \\
\hline \multirow[t]{2}{*}{21} & $\mathrm{M}$ & & F & 2.27 & & & & & & & \\
\hline & & & B & 1.77 & & & & & & & \\
\hline
\end{tabular}

Neck swab procedure: The volunteers were not asked to forgo washing their necks or any other part of their routine procedures (e.g., using perfume or an after-shave lotion). Therefore, the determination of neck skin bacteria was under real life conditions. The skin swabs were collected primarily during the month of February, 2010.

The volunteers took their own neck swabs. Each volunteer was provided with sterile gloves and two sterile, individually wrapped plastic disposable inoculating loops (1 $\mu \mathrm{l}$; Fisher Scientific, 13-075-1). Where appropriate, each volunteer used one gloved hand to move her/his hair and/or clothing aside. The other gloved hand held the sterile loop. One loop was touched to the base of the Front of the neck (overlaying the suprasternal notch) and gently rubbed in a small circle. The loop was placed in a Nalgene cryogenic vial (Thermo Scientific Nalgene) and a sterile scissor was employed to cut the loop into the vial. The vial was immediately placed in a $-70^{\circ} \mathrm{C}$ freezer. The second sterile loop was touched to the base of the Back of the neck (overlaying the posterior cervical vertebrae) and gently rubbed in a small circle and so forth. The loops remained frozen at $-70^{\circ} \mathrm{C}$ until use.

From neck swab to total DNA: Total DNA was isolated individually from each neck swab employing a Qiagen DNeasy Blood and Tissue Kit, as described by the manufacturer. The final product was dialyzed and concentrated by the use of Amicon Ultra Centrifugal Filters (0.5 mL, Ultracel 100k, Millipore Corp.), as directed by the manufacturer. There were $18-22 \mu \mathrm{L}$ of total DNA per swab after purification.

PCR amplification and purification of the V6 and $\mathrm{V} 3$ regions of the $16 \mathrm{~S}$ ribosomal RNA gene (rDNA): For V6, the forward primer was an equimolar mixture of two nondegenerate oligonucleotides: 5'CGTATCGCCTCCCTCGCGCCATCAG[BAR]CAAC GCGAAGAACCTTACC-3' ${ }^{\prime}$ and 5'CGTATCGCCTCCCTCGCGCCATCAG[BAR]ATAC GCGAGGAACCTTACC-3', where the 5' stretches of capital letters were the Titanium forward primers for 
454 Pyrosequencing, TCAG was the sequencing adaptor, [BAR] represented a unique 7 or 8 base barcode and the remaining nucleotides in italic capitals corresponded to positions 967-985 of the rDNA ( $E$. coli numbering; Dethlefsen et al., 2008). The degenerate reverse primer was 5'CTATGCGCCTTGCCAGCCCGCTCAG[BAR]CGAC ARCCATGCASCACCT-3', where the 5' stretch of capital letters was the Titanium reverse primer for 454 Pyrosequencing, TCAG was the sequencing adaptor, [BAR] was the same unique 7 or 8 base barcode as the forward primer and the remaining nucleotides in italic capitals corresponded to positions 1,064-1,046 of the rDNA (E. coli numbering; Dethlefsen et al., 2008).

Analogously, for V3, the forward primer was 5'-CGTATCGCCTCCCTCGCGCCATCAG[BAR]AC TCCTACGGGAGGCAGCAG-3',

where, the nucleotides in italic capitals corresponded to positions 338-357 of the rDNA (E. coli numbering; Dethlefsen et al., 2008). The reverse primer was 5'-CTATGCGCCTTGCCAGCCCGCTCAG[BAR]TT ACCGCGGCTGCTGGCAC-3', where the nucleotides in italic capitals corresponded to positions 533-515 of the rDNA (E. coli numbering; Dethlefsen et al., 2008).

The detailed amplification primer designs are freely available at http://med.stanford.edu/sgtc/bacteria_human_skin.html. These oligonucleotides were purchased as PAGEpurified from Integrated DNA Technologies.

The unique seven or eight base oligonucleotide barcodes (manuscript in preparation) were designed to maximize the difference in base sequence between any two barcodes so that the possibility of mis-assignment caused by synthesis and/or sequencing errors was minimized. Any two barcodes differ in more than two positions. No barcode has a 5' guanine, as the 3' base of the sequencing adaptor is a guanine. No barcode has consecutive identical bases.

Amplification of the V6 and V3 regions was achieved separately with an AmpliTaq Gold DNA Polymerase Kit (Applied Biosystems, Life Sciences). The template composed $2 \mu \mathrm{L}$ of each $50 \mu \mathrm{L}$ reaction. Five identical reactions were run in parallel for each template. The PCR conditions were, as follows (Hyman et al., 2005): $94^{\circ} \mathrm{C}, 3 \mathrm{~min} ; 30$ cycles of $\left[94^{\circ} \mathrm{C}, 15\right.$, $\left.55^{\circ} \mathrm{C}, 45 \mathrm{sec} ; 72^{\circ} \mathrm{C}, 1 \mathrm{~min}\right] ; 72^{\circ} \mathrm{C}, 8 \mathrm{~min} ; 4^{\circ} \mathrm{C}$, indefinitely.

Following amplification, the five identical reactions for each template were pooled. The V6 or V3 DNA was purified by electrophoresis through a $3 \%$ NuSieve 3:1 agarose gel (Lonza Group). Electrophoresis conditions were $100 \mathrm{~V}$ for $1.3 \mathrm{~h}$.
Following electrophoresis, the V6 or V3 band was excised from the gel and purified by use of a QIAquick Gel Extraction Kit (Qiagen). The final product was dialyzed and concentrated by the use of Amicon Ultra Centrifugal Filters $(0.5 \mathrm{~mL}$, Ultracel 100k, Millipore Corp.). Gel-purified amplicons were quantitated by fluorometry using the Quant-iT PicoGreen dsDNA Assay Kit (Invitrogen, Life Sciences). The assay was carried out in duplicate for each purified amplicon and standard. The concentration of each amplicon was calculated by comparison to the standard curve.

Pyrosequencing (Roche 454 Life Sciences): Two barcodes were assigned to each volunteer: one for V6 and the other for V3. In turn, that meant that the Front and Back V6 and V3 products for each volunteer shared a barcode and, therefore, could not be pooled before pyrosequencing. Instead, two pools were constructed: one of all Front DNAs and another of all Back DNAs. Each DNA was present at a concentration of $10^{9}$ molecules per $\mu$ l. Library quality assessment was performed using an Agilent 2100 Bioanalyser (Agilent Technologies) on a DNA 1000 LabChip (Agilent Technologies). Those libraries that had the correct concentrations of amplicons and did not exhibit a primer dimer peak were selected for pyrosequencing.

Emulsion titrations were carried out for each library based on the recommended molecules of library DNA per emulsion-based clonal amplification process (emPCR) bead for using the GS FLX Titanium Lib-A SV Kit from both the A and B ends (454 Life Sciences). Thereby, the amount of each library to be used in emPCR amplification was determined. The scaled-up emPCR was performed using a GS FLX Titanium LibA MV Kit (454 Life Sciences) for each library. A Coulter Particle Counter (model Z1, Beckman Coulter, Inc.,) was employed to quantitate the amplified DNA beads obtained from the emPCR amplification reactions. Two million DNA beads from Back and Front were loaded onto regions one and two of a PicoTiterPlate (454 Life Sciences), respectively. The sequencing run was performed using a GS FLX Titanium Kit with two regions (454 Life Sciences).

Processing the pyrosequence reads. For V6 and V3 and for each region (corresponding to the Front and the Back of the base of the neck), the sequence reads were sorted by barcode and, thereby, assigned to a volunteer. The pyrosequencing reads were stripped of (i) the 5' Titanium primer sequences, (ii) the 3' gene-specific amplification primer sequences, (iii) the sequence 
adaptor sequences and, finally, (iv) the barcode sequences. A data set was created that consisted of each unique sequence obtained for that sample and the number of times that sequence was represented in the sample.

To identify the bacteria corresponding to the Front and Back of the neck for each volunteer, the "CLASSIFIER" software in the "PYROSEQUENCING" section of the Ribosomal Database Project (RDP; Cole et al., 2009) was employed. Only reads that could be classified were considered further. In all cases, the software identified the bacteria by Class. A very few reads in some sets were identified not by Class but by genus: e.g., TM7. In these cases, the reads were subsumed into Class. For the V6 data only, in 26 cases, the software also identified the bacteria by Order. Actinobacteria were divided into Subclasses rather than Order. These were subsumed into Order.

Analyses: The Shannon Diversity Index (SDI) was calculated for the microbiome of each neck swab (http://math.hws.edu/javamath/ryan/DiversityTest.html) Chao1, Principal Component and SDI analyses employed the QIIME software (Caporaso et al., 2010) with UniFrac distances (Lozupone et al., 2011).

\section{RESULTS AND DISCUSSION}

From the 40 volunteers, there were 80 neck swabs (40 from the Front of the base of the neck; 40 from the Back of the base of the neck; Table 1). Bacteria were identified by 454 Tag pyrosequencing of two short regions (V6 and V3) of rDNA (Huse et al., 2008). We had swab DNA sufficient for only one attempt at amplifying V6 and V3 from each clinical sample. For V6, both swabs for volunteer 04 and the Back swab for volunteer 20 failed to produce any data. Therefore, the following results are derived from the V6 data for 77 swabs.

The bacteria on all 77 swabs were classified into Class. The microbes on 26 swabs (one-third of the total) were classified further into Order. Presumably, our data and the RDP software were the sole determinants for which samples the bacteria could be identified by Order. The raw data are freely available at http://med.stanford.edu/sgtc/bacteria_human_skin.html.

The V6 bacterial identifications for all 77 swabs are presented in Table 2A (Class) and 3 (Order), listing only those bacteria supported by, at least, $1 \%$ of the reads.

The parameters for the V6 Class data are shown in Table 4A. There was a total of 166,051 reads for V6
Front $(\mathrm{V} 6 \mathrm{~F} ; \mathrm{n}=39)$ and 119,042 reads for V6 Back $(\mathrm{V} 6 \mathrm{~B} ; \mathrm{n}=38)$. The average number of reads per swab was $4257+/-2138$ for V6F and $3132+/-1382$ for V6B. By the two-sided t-test, these two numbers were statistically significantly different $(p=0.0078)$. A difference was not surprising as the two sets of swabs were sequenced separately (Materials and Methods). The average total percent of those bacteria comprising at least $1 \%$ of the reads was $98.3+/-1.0 \%$ for $\mathrm{V} 6 \mathrm{~F}$ and $98.7+/-0.7 \%$ for V6B. These two numbers were on the border of being statistically significantly different $(\mathrm{p}=$ 0.046). The very high average percentages demonstrated that nearly all of the bacteria on each swab were accounted for when the focus was on only those bacteria that comprise, at least, $1 \%$ of the reads for each swab.

Pyrosequencing produced a total of 285,093 classified reads for V6 (Table 4A). To estimate how close the data were to saturation, Chao1 analyses were performed. The results for both Front and Back swabs are shown in Fig. 1. The curves for the Front and Back swabs were indistinguishable. Neither curve appeared close to saturation.

The sums of the V6 skin bacterial identifications are presented in Table 5. For Class (Table 5A), all 77 of the swabs contained, at least, $1 \%$ of the reads as Actinobacteria and Gammaproteobacteria. The substantial majority of the swabs contained, at least, $1 \%$ of the reads as Alphaproteobacteria, Bacilli and Betaproteobacteria. About half of the swabs contained, at least, $1 \%$ of the reads as Flavobacteria and Sphingobacteria. A few swabs contained Clostridia or Cyanobacteria, at least at the $1 \%$ level (Table 5A). (Flavobacteria, Sphingobacteria, Clostridia and Cyanobacteria were present on many more swabs, but were supported by less than $1 \%$ of the reads on those swabs.) The Class of Gammaproteobacteria was supported by the most reads for 72 of 77 swabs (94\%, Table 2A). For the remaining five swabs, the Class of Actinobacteria was supported by the most reads on three. The Class of Bacilli was supported by the most reads on two.

The average percentages of V6 reads supporting the three most abundant bacterial Classes (Actinobacteria, Bacilli, Gammaproteobacteria) are shown in Table 6A. The ranges of percentages for the Actinobacteria, Bacilli and Gammaproteobacteria reads were very large. For the Front swabs, the ranges were as follows: Actinobacteria, 2.2 to 49.3\%; Bacilli, 0.4-44.8\%; and Gammaproteobacteria 30.0-97.4\%. For the Back swabs, the ranges were Actinobacteria, 1.9-45.5\%; Bacilli, 0.739.8\%; Gammaproteobacteria, 20.3-85.7\%. 
Am. J. Microbiology 2 (2): 25-34, 2011

Table 2A: Bacteria by Class on individual swabs: listing those bacteria supported by at least $1 \%$ of the reads: V6

\begin{tabular}{|c|c|c|c|c|c|c|c|c|c|c|c|c|}
\hline $\begin{array}{l}\text { Voluntee } \\
\text { ID }\end{array}$ & $(\%)$ & Actinobacteria & Alphaproteobacteria & Bacilli & Betaproteobacteria & Clostridia & Cyanobacteria & Flavobacteria & Gammaproteobacteria & Sphingobacteria & $\begin{array}{l}\text { Total } \\
(\%)\end{array}$ & $\begin{array}{l}\text { Total } \\
\text { reads }\end{array}$ \\
\hline \multirow[t]{2}{*}{1} & Front & 5.8 & 1.3 & 27.1 & 1.3 & & & & 63.4 & & 98.9 & 8036 \\
\hline & Back & 9.9 & 1.4 & 3.9 & 1.7 & & & & 81.5 & & 98.4 & 7113 \\
\hline \multirow[t]{2}{*}{2} & Front & 22.8 & 2.7 & 3.9 & 1.3 & & & & 67.9 & & 98.6 & 6052 \\
\hline & Back & 18.3 & 2.6 & 2.4 & 1.3 & & & & 74.7 & & 99.3 & 3405 \\
\hline \multirow[t]{2}{*}{3} & Front & 6.2 & 1.3 & 3.7 & 1.5 & & & & 85.6 & & 98.4 & 2752 \\
\hline & Back & 12.8 & 1.2 & 4.6 & & & & & 79.2 & & 97.8 & 1923 \\
\hline \multirow[t]{2}{*}{5} & Front & 11.3 & 1.0 & & 2.1 & & & & 79.7 & & 94.1 & 2300 \\
\hline & Back & 31.1 & 1.3 & 3.7 & 1.6 & & & & 59.9 & & 97.6 & 3209 \\
\hline 6 & Front & 11.2 & 1.5 & 3.1 & 1.6 & & & & 80.8 & & 98.2 & 2712 \\
\hline & Back & 20.3 & & 3.3 & 1.7 & & & & 72.9 & & 98.2 & 2475 \\
\hline 7 & Front & 19.0 & 2.3 & 2.8 & 2.1 & & & & 72.2 & & 98.4 & 2144 \\
\hline & Back & 25.2 & 3.3 & 4.1 & 2.2 & & & & 63.2 & & 98.0 & 821 \\
\hline 8 & Front & 5.5 & 1.3 & 4.4 & 2.0 & & 1.1 & & 84.4 & & 98.7 & 4893 \\
\hline & Back & 6.8 & 1.7 & 4.8 & 1.5 & & & & 82.4 & & 97.2 & 3718 \\
\hline 9 & Front & 9.6 & 6.1 & 5.4 & 1.7 & & & 1.1 & 73.7 & 1.6 & 99.0 & 6093 \\
\hline & Back & 6.1 & 7.3 & 5.2 & 2.2 & & 1.3 & & 74.1 & 2.1 & 98.3 & 4204 \\
\hline 10 & Front & 12.9 & & 1.5 & 1.3 & & & & 81.4 & & 97.0 & 7330 \\
\hline & Back & 28.8 & 2.0 & 2.7 & 1.4 & & & & 63.8 & & 98.6 & 4006 \\
\hline 11 & Front & 5.8 & 1.4 & 2.5 & 2.7 & & & & 85.0 & & 97.4 & 11595 \\
\hline & Back & 7.0 & 1.2 & 2.0 & 2.4 & & & & 85.7 & & 98.3 & 3563 \\
\hline 12 & Front & 17.1 & 1.7 & 11.5 & 1.2 & 1.2 & & & 65.4 & & 98.1 & 3731 \\
\hline & Back & 10.0 & 2.4 & 2.2 & 1.4 & & & 1.9 & 80.8 & & 98.7 & 4429 \\
\hline 13 & Front & 13.5 & 3.8 & 7.3 & 1.6 & & & 2.8 & 67.8 & 1.2 & 98.0 & 6562 \\
\hline & Back & 12.7 & 3.6 & 4.8 & 1.9 & & & 3.3 & 70.7 & 1.9 & 98.9 & 4302 \\
\hline 14 & Front & 9.5 & 5.9 & 3.0 & 3.3 & & & & 75.2 & 1.5 & 98.4 & 7455 \\
\hline & Back & 9.7 & 5.5 & 2.1 & 2.8 & & 1.1 & & 76.1 & 1.4 & 98.7 & 3940 \\
\hline 15 & Front & 32.0 & 8.9 & 5.0 & 2.0 & & & & 49.3 & & 97.2 & 4361 \\
\hline & Back & 41.3 & 5.9 & 2.5 & 1.9 & & & & 47.2 & & 98.8 & 2143 \\
\hline 16 & Front & 36.8 & & 8.6 & & & & & 50.5 & & 95.9 & 3892 \\
\hline & Back & 20.4 & 8.4 & 4.3 & & 1.5 & & & 64.0 & & 98.6 & 2408 \\
\hline 17 & Front & 13.2 & 1.0 & 2.1 & 1.9 & & & & 80.3 & & 98.5 & 3172 \\
\hline & Back & 11.4 & 2.5 & 3.6 & 1.5 & & & & 78.5 & & 97.5 & 4125 \\
\hline 18 & Front & 4.7 & 1.5 & 44.8 & 1.2 & & & & 46.5 & & 98.7 & 4480 \\
\hline & Back & 31.5 & 1.2 & 14.7 & 1.1 & & & & 49.2 & & 97.7 & 3981 \\
\hline 19 & Front & 6.3 & 4.2 & 2.5 & 2.9 & & & & 82.0 & 1.3 & 99.2 & 2286 \\
\hline & Back & 38.3 & 1.9 & 5.5 & 1.0 & & & & 51.8 & & 98.5 & 1824 \\
\hline 20 & Front & 6.1 & 3.9 & 1.8 & 3.0 & & 1.7 & & 82.1 & & 98.6 & 4881 \\
\hline 21 & Front & 19.8 & & 2.3 & 2.8 & & & 3.4 & 67.6 & 2.6 & 98.5 & 2705 \\
\hline & Back & 19.1 & 1.0 & 4.1 & 3.7 & & & 4.5 & 64.4 & 2.8 & 99.6 & 4745 \\
\hline 22 & Front & 10.8 & 1.4 & 3.5 & 4.4 & & & 6.4 & 68.0 & 4.7 & 99.2 & 4852 \\
\hline & Back & 8.6 & 1.9 & 8.1 & 5.2 & & & 5.5 & 66.0 & 4.3 & 99.6 & 4890 \\
\hline 23 & Front & 7.7 & 4.4 & 1.4 & 2.4 & & & & 80.6 & 1.7 & 98.2 & 4364 \\
\hline & Back & 11.8 & 3.4 & 8.2 & 2.9 & & & & 70.5 & 1.8 & 98.6 & 3141 \\
\hline 24 & Front & 10.6 & 2.2 & 13.2 & 3.8 & & & 4.6 & 61.3 & 3.0 & 98.7 & 7201 \\
\hline & Back & 12.0 & 1.7 & 30.0 & 2.6 & & & 3.5 & 48.0 & 2.1 & 99.9 & 4545 \\
\hline 25 & Front & 38.1 & & 3.9 & 2.6 & & & 3.2 & 48.6 & 2.5 & 98.9 & 3908 \\
\hline & Back & 45.5 & 3.9 & 2.3 & 1.9 & & & 3.2 & 40.8 & 1.8 & 99.4 & 3026 \\
\hline 26 & Front & 26.4 & 1.7 & 5.8 & 3.2 & & & 3.0 & 55.9 & 2.7 & 98.4 & 1607 \\
\hline & Back & 24.7 & 1.1 & 3.3 & 3.8 & & & 4.3 & 58.7 & 3.2 & 99.1 & 2258 \\
\hline 27 & Front & 49.3 & 3.3 & 9.8 & 1.8 & & & & 34.0 & & 98.2 & 3304 \\
\hline & Back & 31.3 & 4.7 & 5.2 & 1.4 & & & & 56.1 & & 98.7 & 3065 \\
\hline 28 & Front & 20.6 & 3.1 & 6.3 & 1.8 & & & & 65.7 & & 97.5 & 4346 \\
\hline & Back & 32.6 & 2.0 & 7.1 & & & & & 55.8 & & 97.5 & 3343 \\
\hline 29 & Front & 30.4 & 1.1 & 36.6 & & & & & 30.0 & & 98.1 & 2524 \\
\hline & Back & 7.4 & 2.1 & 11.1 & 1.1 & & & & 77.0 & & 98.7 & 2336 \\
\hline 30 & Front & 47.9 & 1.3 & 17.9 & 1.1 & & & & 30.8 & & 99.0 & 6598 \\
\hline & Back & 12.2 & 2.7 & 7.5 & 1.9 & & & & 73.6 & & 97.9 & 6017 \\
\hline 31 & Front & 17.6 & 3.9 & 2.6 & 4.6 & & & 5.8 & 59.6 & 4.8 & 98.9 & 5314 \\
\hline & Back & 24.1 & 3.7 & 3.6 & 3.7 & & & 4.8 & 55.4 & 4.0 & 99.3 & 4098 \\
\hline 32 & Front & 20.5 & 3.0 & 3.4 & 3.9 & & & 6.0 & 57.8 & 4.8 & 99.4 & 4960 \\
\hline & Back & 9.1 & 4.0 & 1.1 & 4.6 & & & 6.9 & 69.7 & 4.2 & 99.6 & 3101 \\
\hline 33 & Front & 2.2 & 2.1 & & 4.4 & & & 4.7 & 82.7 & 2.9 & 99.0 & 2812 \\
\hline & Back & 1.9 & 3.2 & & 3.5 & & & 4.2 & 84.0 & 2.2 & 99.0 & 2285 \\
\hline 34 & Front & 5.1 & 1.9 & & 3.9 & & & 5.6 & 78.9 & 3.4 & 98.8 & 2393 \\
\hline & Back & 2.1 & 2.3 & 1.0 & 3.9 & & 4.2 & 5.3 & 77.7 & 3.1 & 99.6 & 1683 \\
\hline 35 & Front & 28.8 & & 30.2 & 1.0 & & & 1.5 & 37.1 & & 98.6 & 3969 \\
\hline & Back & 35.8 & & 39.8 & & & & 1.6 & 20.3 & 1.4 & 98.9 & 1481 \\
\hline 36 & Front & 21.9 & 1.9 & 2.4 & 1.6 & & & 2.6 & 66.9 & 2.1 & 99.4 & 2051 \\
\hline & Back & 23.4 & 3.5 & 2.4 & 1.9 & & & 2.8 & 64.6 & 1.2 & 99.8 & 964 \\
\hline 37 & Front & 39.7 & 1.3 & 14.1 & 2.6 & & & 2.0 & 37.9 & 1.4 & 99.0 & 2764 \\
\hline & Back & 19.7 & 1.6 & 11.3 & 3.5 & & & 3.0 & 57.9 & 2.1 & 99.1 & 2258 \\
\hline 38 & Front & 17.8 & 1.7 & 8.6 & 2.7 & & & 3.3 & 62.8 & 1.5 & 98.4 & 1774 \\
\hline & Back & 17.9 & 1.1 & 4.8 & 1.9 & & & 3.1 & 68.7 & 2.4 & 99.9 & 1573 \\
\hline 39 & Front & 4.9 & 1.0 & 1.6 & 3.3 & & & 4.0 & 82.7 & 2.0 & 99.5 & 1981 \\
\hline & Back & 3.2 & 1.5 & 6.2 & 3.3 & & & 3.0 & 80.2 & 2.4 & 99.8 & 1248 \\
\hline 40 & Front & 10.4 & & 13.8 & 2.6 & & & 3.2 & 66.4 & 2.2 & 98.6 & 1897 \\
\hline & Back & 12.0 & & 29.1 & 2.3 & & & 3.1 & 50.1 & 2.2 & 98.8 & 1396 \\
\hline
\end{tabular}


Am. J. Microbiology 2 (2): 25-34, 2011

Table 2B: Bacteria by Class on individual swabs: listing those bacteria supported by at least $1 \%$ of the reads: V3

\begin{tabular}{|c|c|c|c|c|c|c|c|c|c|c|c|c|}
\hline $\begin{array}{l}\text { Volunteer } \\
\text { ID }\end{array}$ & $(\%)$ & Actinobacteria & Alphaproteobacteria & Bacilli & Betaproteobacteria & Clostridia & Cyanobacteria & Flavobacteria & Gammaproteobacteria & Sphingobacteria & $\begin{array}{l}\text { Total } \\
\%\end{array}$ & $\begin{array}{l}\text { Total } \\
\text { reads }\end{array}$ \\
\hline 15 & Back & 87.6 & & 2.3 & & & & & 8.2 & & 98.1 & 5098 \\
\hline 16 & Front & 62.1 & & 16.2 & 2.5 & 1.7 & & & 13.6 & & 97.9 & 10680 \\
\hline 18 & Back & 10.6 & & 69.1 & & & 1.3 & & 16.6 & & 97.6 & 4838 \\
\hline 19 & Back & 82.3 & & 5.30 & 1.1 & & & & 8.90 & & 97.6 & 2815 \\
\hline 24 & Back & 23.1 & & 54.9 & 1.6 & & & 5.9 & 11.5 & 1.5 & 98.5 & 8557 \\
\hline 25 & Back & 85.5 & & 2.4 .0 & & & & 2.9 & 5.90 & & 96.7 & 6262 \\
\hline 27 & Front & 80.0 & & 11.4 & & & 2.1 & & 4.40 & & 97.9 & 5582 \\
\hline 29 & Front & 31.4 & & 65.2 & & & & & 2.50 & & 99.1 & 6304 \\
\hline 30 & Front & 90.6 & & 4.30 & & & & & 3.10 & & 98.0 & 6451 \\
\hline \multirow[t]{2}{*}{32} & Front & 52.9 & 1.2 & 9.60 & 4.9 & & & 14.1 & 10.1 & 4.2 & 97.0 & 5926 \\
\hline & Back & 70.1 & & 2.30 & 3.6 & & & 10.2 & 9.60 & 2.6 & 98.4 & 8632 \\
\hline 33 & Front & 67.3 & 1.4 & 1.90 & 3.5 & & & 10.8 & 10.2 & 3.1 & 98.2 & 9129 \\
\hline \multirow[t]{2}{*}{36} & Front & 80.3 & & 2.40 & 1.3 & 1.1 & & 5.30 & 6.30 & 1.3 & 98.0 & 5662 \\
\hline & Back & 82.9 & 2.3 & 1.20 & 1.2 & 1.8 & & 3.70 & 5.00 & & 98.1 & 4785 \\
\hline 38 & Front & 44.8 & 1.4 & 17.3 & 4.4 & 2 & & 9.00 & 14.0 & 2.5 & 97.7 & 7373 \\
\hline \multirow[t]{2}{*}{40} & Front & 21.1 & 1.5 & 41.9 & 4.4 & & & 10.1 & 15.5 & 2.6 & 97.1 & 7097 \\
\hline & Back & 18.9 & & 56.5 & 2.8 & & & 7.40 & 10.0 & 2.3 & 97.9 & 4283 \\
\hline
\end{tabular}

Table 3: Bacteria by Order on individual swabs: listing those bacteria supported by, at least, $1 \%$ of the reads: V6

\begin{tabular}{|c|c|c|c|c|c|c|c|c|c|c|c|c|c|c|c|c|c|c|c|c|}
\hline $\begin{array}{l}\text { Volunteer } \\
\text { ID }\end{array}$ & $(\%)$ & $\begin{array}{l}\text { Actinoba } \\
\text { cteridae }\end{array}$ & $\begin{array}{l}\text { Alteromo } \\
\text { nadales }\end{array}$ & $\begin{array}{l}\text { Baci } \\
\text { llales }\end{array}$ & $\begin{array}{l}\text { Burkhol } \\
\text { deriales }\end{array}$ & $\begin{array}{l}\text { Cauloba } \\
\text { cterales }\end{array}$ & $\begin{array}{l}\text { Chloro } \\
\text { plast }\end{array}$ & $\begin{array}{l}\text { Chroma } \\
\text { tiales }\end{array}$ & $\begin{array}{l}\text { Clostri } \\
\text { diales }\end{array}$ & $\begin{array}{l}\text { Enteroba } \\
\text { cteriales }\end{array}$ & $\begin{array}{l}\text { Flavobac } \\
\text { teriales }\end{array}$ & $\begin{array}{l}\text { Lactoba } \\
\text { cillales }\end{array}$ & $\begin{array}{l}\text { Pseudomo } \\
\text { nadales }\end{array}$ & $\begin{array}{l}\text { Rhizo } \\
\text { biales }\end{array}$ & $\begin{array}{l}\text { Rhodos } \\
\text { pirillales }\end{array}$ & $\begin{array}{l}\text { Sphingoba } \\
\text { cteriales }\end{array}$ & $\begin{array}{l}\text { Sphingomo } \\
\text { nadales }\end{array}$ & $\begin{array}{l}\text { Xanthomo } \\
\text { nadales }\end{array}$ & $\begin{array}{l}\text { Total } \\
\%\end{array}$ & $\begin{array}{l}\text { Total } \\
\text { reads }\end{array}$ \\
\hline 3 & Back & 19.2 & 3.7 & 4.1 & & & & 2.6 & & 61.8 & 1.0 & 1.6 & 1.0 & & & & & & 95.0 & 1262 \\
\hline 5 & Front & 17.1 & 4.6 & 3.5 & 2.6 & & 1.1 & 3.1 & & 60.8 & & & 2.2 & & & & & & 95.0 & 1506 \\
\hline \multirow[t]{2}{*}{7} & Front & 27.5 & 2.4 & 1.6 & 2.9 & & & 2.2 & & 52.1 & & 1.2 & 2.9 & 1.2 & & & & 1.4 & 95.4 & 1473 \\
\hline & Back & 34.4 & 2.3 & 2.5 & 2.7 & & & 2.2 & & 44.2 & & & 3.0 & 1.2 & & & & 1.0 & 93.5 & 599 \\
\hline \multirow[t]{2}{*}{15} & Front & 40.8 & 1.6 & 4.2 & 1.9 & & & 1.2 & & 30.8 & 1.2 & 1.0 & 1.3 & 9.0 & & & & 1.7 & 94.7 & 3399 \\
\hline & Back & 51.9 & 1.5 & 1.8 & 2.2 & & & 1.2 & & 30.6 & & & & 6.1 & & & & & 95.3 & 1702 \\
\hline 16 & Back & 30.0 & 2.4 & 4.2 & 1.0 & & & 1.8 & 2.0 & 45.6 & & & 1.5 & 8.3 & 1.3 & & & & 98.1 & 1736 \\
\hline 17 & Front & 20.1 & 2.6 & 1.9 & 2.3 & & & 2.5 & & 63.3 & & & 1.9 & & & & & & 94.6 & 2076 \\
\hline \multirow[t]{2}{*}{19} & Front & 9.8 & 2.8 & 1.8 & 3.7 & 1.2 & & 3.1 & & 64.7 & & & 1.9 & 3.3 & & 2.1 & & 1.5 & 95.9 & 1441 \\
\hline & Back & 49.0 & 1.7 & 4.2 & 1.1 & & & 1.6 & & 35.4 & & & 1.1 & & & & & & 94.1 & 1420 \\
\hline 23 & Back & 17.2 & 2.3 & 10.2 & 3.9 & & & 2.3 & & 50.3 & 1.1 & & 1.5 & 3.1 & & 2.6 & & 2.1 & 96.6 & 2123 \\
\hline \multirow[t]{2}{*}{25} & Back & 55.4 & 1.2 & 1.7 & 1.6 & & & & & 24.9 & 4.0 & & 1.2 & 4.3 & & 2.2 & & & 96.5 & 2422 \\
\hline & Front & 60.8 & & 6.0 & 1.1 & & & & & 20.2 & & 2.2 & & 3.2 & & & & & 93.5 & 2652 \\
\hline 27 & Back & 41.7 & 1.6 & 5.2 & 1.6 & & & 1.6 & & 36.5 & & & 1.7 & 5.4 & & & & & 95.3 & 2261 \\
\hline 28 & Back & 44.9 & 1.3 & 5.0 & & & & 1.6 & & 37.8 & & 1.2 & 1.5 & 1.4 & & & & & 94.7 & 2419 \\
\hline \multirow[t]{2}{*}{29} & Back & 12.0 & 4.4 & 14.8 & 1.3 & & & 4.7 & & 54.0 & 1.0 & & 1.7 & 1.7 & & & & & 95.6 & 1434 \\
\hline & Front & 58.5 & & 16.2 & 1.0 & & & & & 18.3 & & & & & & & & & 94.0 & 5394 \\
\hline 30 & Back & 18.0 & 2.8 & 9.3 & 2.3 & & & 2.4 & & 54.8 & & & 1.9 & 1.4 & & 1.1 & & 1.4 & 95.4 & 4071 \\
\hline \multirow[t]{2}{*}{34} & Back & 3.2 & 2.4 & & 3.5 & & 6.7 & 1.5 & & 62.2 & 8.5 & & & 1.1 & & 5.0 & 1.0 & & 95.1 & 1057 \\
\hline & Front & 35.0 & & 36.9 & & & & & & 22.0 & 2.0 & & & & & 1.1 & & & 97.0 & 3071 \\
\hline 35 & Back & 39.3 & & 43.0 & & & & & & 11.8 & 1.8 & & & & & 1.5 & & & 97.4 & 1307 \\
\hline 36 & Back & 34.4 & & $\begin{array}{l}1.7 \\
\end{array}$ & 1.4 & & & 1.1 & & $\begin{array}{l}46.9 \\
\end{array}$ & $\begin{array}{l}4.1 \\
4.1\end{array}$ & & & 1.5 & 2.3 & 1.8 & & 1.1 & 96.3 & 657 \\
\hline 37 & Back & 27.5 & & 12.5 & 2.8 & & & & & 42.4 & 4.2 & & & 1.2 & & 2.9 & & & 93.5 & 1602 \\
\hline 38 & Back & 26.7 & 1.0 & 6.4 & 1.3 & & & & & 50.7 & 4.6 & & 1.1 & & & 3.6 & & & 95.4 & 1046 \\
\hline 39 & Back & 5.1 & 1.4 & 7.2 & 2.9 & & & 1.3 & & 66.4 & 5.0 & & 2.2 & 1.3 & & 3.9 & & & 96.7 & 763 \\
\hline 40 & Back & 16.2 & 1.4 & 35.4 & 1.8 & & & 1.4 & & 31.9 & 4.2 & & 1.7 & & & 3.0 & & & 97.0 & 1030 \\
\hline
\end{tabular}

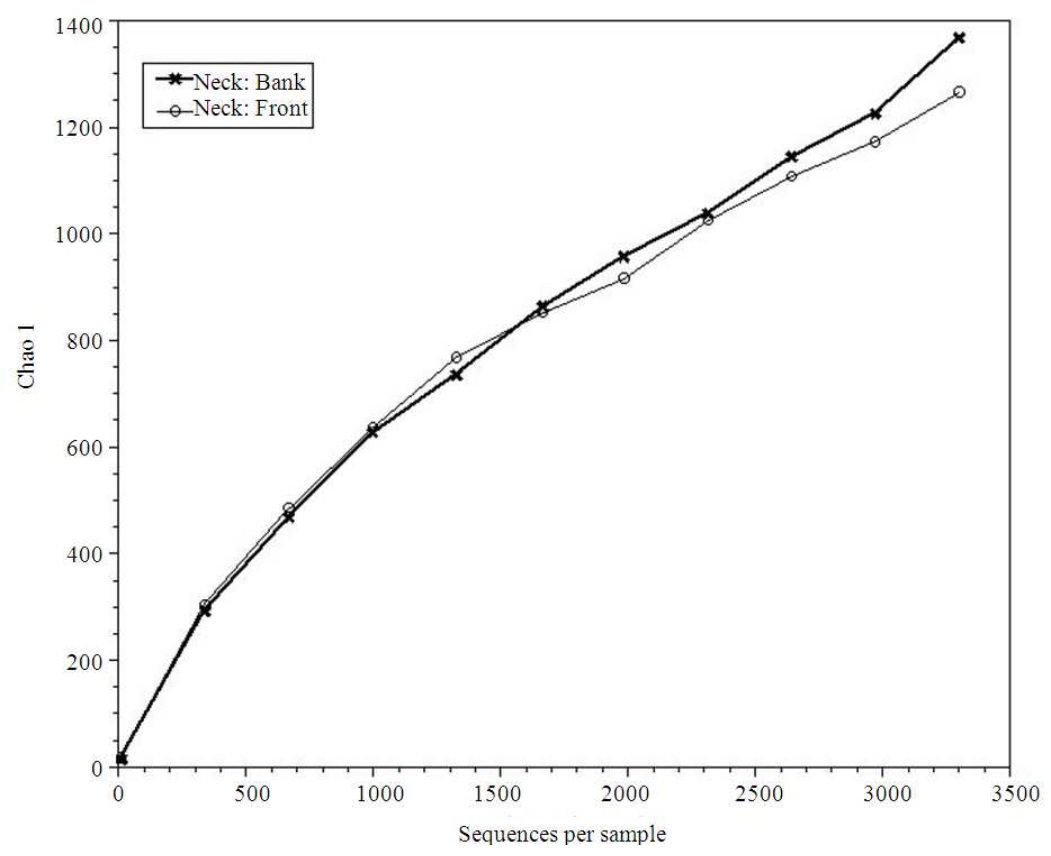

Fig. 1: Chao1 analyses of the V6 data from the Front of the base of the neck and the Back of the base of the neck 
Am. J. Microbiology 2 (2): 25-34, 2011

All possible statistical comparisons were carried out. None of the comparisons of these averages yielded a statistically significant difference: Front could not be distinguished from Back; males could not be distinguished from females (Table 6A and data not shown). As one example, the average percent $(65.7+/-$ $16.7 \% ; n=39$ ) of Gammaproteobacteria on the V6 Front swabs was not statistically significantly different from the average percent $(65.3+/-13.6 \% ; \mathrm{n}=38)$ of Gammaproteobacteria on the V6 Back swabs $(\mathrm{p}=0.91)$.

In comparing the bacteria on the Front and Back swabs for each individual, the first focus was on the bacterium supported by the most V6 reads. For five volunteers, the Front and Back swabs had a different principal bacterium (volunteers 27, 29, 30, 35, 37; Table 2A). For example, for volunteer 37, the Class of bacteria supported by the most V6 reads $(39.7 \%)$ on the Front swab was Actinobacteria while the bacterial Class supported by the most V6 reads $(57.9 \%)$ on the Back swab was Gammaproteobacteria. In addition, for volunteer 18's Front and Back swabs, the number of reads supporting two major Classes of bacteria were different: Actinobacteria, 4.7\% Front, 31.5\% Back; Bacilli, 44.8\% Front, 14.7\% Back (Table 2A). Thus, for these six volunteers $(6 / 38=16 \%)$, the bacterial mix was different on the Front of the base of the neck compared to the Back of the base of the neck. For volunteer 19's swabs, the read support for two bacteria differed by more than an absolute $20 \%$ : Actinobacteria, 6.3\% Front, 38.3\% Back; Gammaproteobacteria, 82.0\% Front, $51.8 \%$ Back (Table 2A). For an additional nine volunteers $(01,05,10,12,16,23,24,32,40)$, the number of reads supporting the most abundant Class of bacteria on the Front swab was, at least, an absolute $10 \%$ different from the bacterial Class supported by the most reads on the Back swab (Table 2A). For example, for volunteer 40, the Class of Gammaproteobacteria on the Front swab was supported by $66.4 \%$ of the reads, while the Class of Gammaproteobacteria on the Back swab was supported by $50.1 \%$ of the reads. The results of Principal Component analyses are shown in Fig. 2. No obvious grouping occurred on the basis of gender (female/male) or location (Front/Back).

The diversity of the bacteria on the swabs was considered. The average number of bacteria by Class on the Front swabs was $13.1+/-2.0(\mathrm{n}=39$; Table 2A). The average number of bacteria on the Back swabs was $12.0+/-2.0(\mathrm{n}=38$; Table $2 \mathrm{~A})$. The bacterial diversity within each swab was examined by computing the Shannon Diversity Index (SDI) for each swab (Table 1). For the Class data, the average SDI for the Front swabs was $2.20+/-0.35(\mathrm{n}=39)$ and the Back swabs $2.06+/-0.41(\mathrm{n}=38)$.
Table 4: Parameters for the V6 data

\begin{tabular}{|c|c|c|}
\hline & V6F & V6B \\
\hline \multicolumn{3}{|l|}{ A Class } \\
\hline $\begin{array}{l}\text { Total reads } \\
(\mathrm{n}=39)(\mathrm{n}=38)\end{array}$ & $166,051119,042$ & \\
\hline Average reads/swab & $4,257+/-2,138$ & $3,132+/-1,382$ \\
\hline Percent total & $98.3+/-1.0^{\mathrm{a}}$ & $98.7+/-0.7^{\mathrm{a}}$ \\
\hline \multicolumn{3}{|l|}{ B Order } \\
\hline $\begin{array}{l}\text { Total reads } \\
(\mathrm{n}=8)(\mathrm{n}=18)\end{array}$ & $21,01228,911$ & \\
\hline Average reads/swab & $2626+/-1262$ & $1606+/-815$ \\
\hline Percent total & $95.0+/-1.0^{\mathrm{a}}$ & $95.6+/-1.2^{\mathrm{a}}$ \\
\hline
\end{tabular}

as with at least $1 \%$ of the reads

Table 5: Skin bacteria identification (with at least $1 \%$ of the reads)

\begin{tabular}{lrrrrrr}
\hline & \multicolumn{7}{c}{ Total } & \multicolumn{2}{c}{ V6 Front } & \multicolumn{3}{c}{ V6 Back } \\
Class & Number $(\%)$ & Number $(\%)$ & Number $(\%)$ \\
\hline A Class & & & & & & \\
Actinobacteria & 77 & 100 & 39 & 100.0 & 38 & 100.0 \\
Alphaproteobacteria & 68 & 88.3 & 33 & 84.6 & 35 & 92.1 \\
Bacilli & 73 & 94.8 & 36 & 92.3 & 37 & 97.4 \\
Betaproteobacteria & 71 & 92.2 & 37 & 94.9 & 34 & 89.5 \\
Clostridia & 2 & 2.6 & 1 & 2.6 & 1 & 2.6 \\
Cyanobacteria & 5 & 6.5 & 2 & 5.1 & 3 & 7.9 \\
Flavobacteria & 35 & 45.5 & 17 & 43.6 & 18 & 47.4 \\
Gammaproteobacteria & 77 & 100.0 & 39 & 100.0 & 38 & 100.0 \\
Sphingobacteria & 38 & 49.4 & 19 & 48.7 & 19 & 50.0 \\
B Order & & & & & & \\
Actinobacteridae & 26 & 100.0 & 8 & 100.0 & 18 & 100.0 \\
Alteromonadales & 20 & 76.9 & 5 & 62.5 & 15 & 83.3 \\
Bacillales & 25 & 96.2 & 8 & 100.0 & 17 & 94.4 \\
Burkholderiales & 22 & 84.6 & 7 & 87.5 & 15 & 83.3 \\
Caulobacterales & 1 & 3.8 & 1 & 12.5 & 0 & 0.0 \\
Chloroplast & 2 & 7.7 & 1 & 12.5 & 1 & 5.6 \\
Chromatiales & 19 & 73.1 & 5 & 62.5 & 14 & 77.8 \\
Clostridiales & 1 & 3.8 & 0 & 0.0 & 1 & 5.6 \\
Enterobacteriales & 26 & 100.0 & 8 & 100.0 & 18 & 100.0 \\
Flavobacteriales & 13 & 50.0 & 2 & 25.0 & 11 & 61.1 \\
Lactobacillales & 5 & 19.2 & 3 & 37.5 & 2 & 11.1 \\
Pseudomonadales & 18 & 69.2 & 5 & 62.5 & 13 & 72.2 \\
Rhizobiales & 17 & 65.4 & 4 & 50.0 & 13 & 72.2 \\
Rhodospirillales & 2 & 7.7 & 0 & 0.0 & 2 & 11.1 \\
Sphingobacteriales & 12 & 46.2 & 2 & 25.0 & 10 & 55.6 \\
Sphingomonadales & 1 & 3.8 & 0 & 0.0 & 1 & 5.6 \\
Xanthomonadales & 7 & 26.9 & 3 & 37.5 & 4 & 22.2 \\
\hline & & & & & &
\end{tabular}

Table 6: Bacterial content comparisons

\begin{tabular}{llll}
\hline Bacterium & Front (average $\%)$ & Back (average $\%)$ & p-value \\
\hline A Class & & & \\
Actinobacteria & $17.4+/-12.3$ & $18.3+/-11.4$ & 0.74 \\
Male & $19.3+/-13.1$ & $20.0+/-11.7$ & \\
Female & $13.2+/-8.7$ & $14.1+/-9.1$ & \\
Bacilli & $8.3+/-10.0$ & $6.9+/-8.3$ & 0.50 \\
Male & $9.1+/-10.1$ & $7.0+/-8.5$ & \\
Female & $6.6+/-9.7$ & $6.7+/-7.6$ & 0.91 \\
Gammaproteobacteria & $65.7 /-16.7$ & $65.3+/-13.6$ & \\
B Order & & & \\
Male & $62.5+/-15.8$ & $63.2+/-14.0$ & 0.51 \\
Female & $72.8+/-16.5$ & $70.4+/-10.9$ & \\
Actinobacteridae & $33.7+/-17.6$ & $29.2+/-15.3$ & \\
Male & $34.5+/-18.6$ & $31.7+/-16.4$ & \\
Female & 27.5 & $22.8+/-9.6$ & \\
Bacillales & $9.0+/-11.4$ & $9.4+/-11.2$ & \\
Male & $10.0+/-11.8$ & $8.1+/-10.5$ & \\
Female & 1.6 & $12.9+/-12.2$ & \\
Enterobacteriales & $41.5+/-19.3$ & $43.8+/-13.6$ & \\
Male & $40.0+/-20.2$ & $43.1+/-15.3$ & \\
Female & 52.1 & $45.4+/-7.5$ & \\
\hline
\end{tabular}



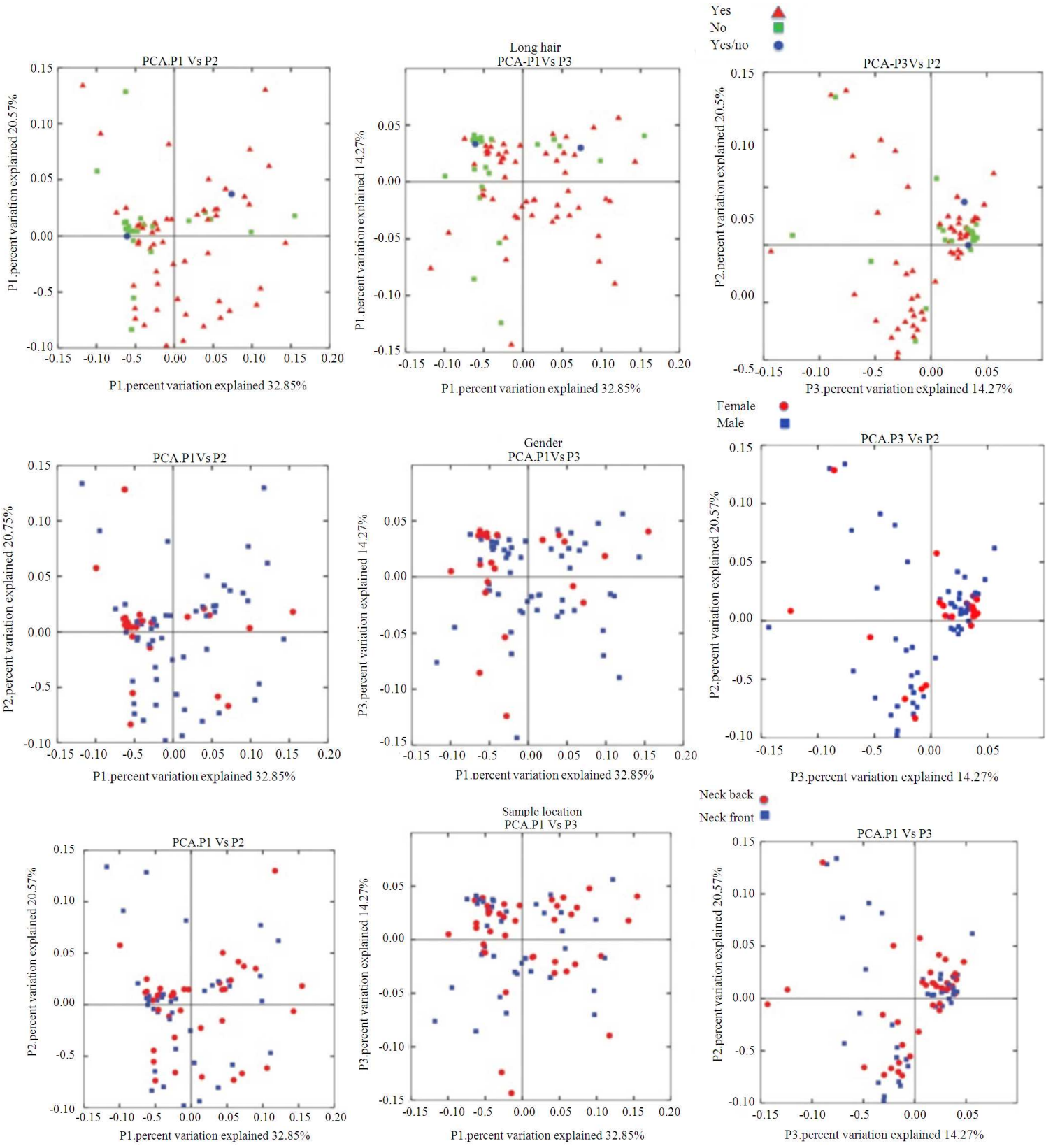

Fig. 2: Principal component analyses of the V6 data

The SDI was considered as a function of the number of reads (Fig. 3). The Front and Back curves were indistinguishable.

For the V6 Order data, there was a total of 21,012 reads for V6F $(n=8)$ and 28,911 reads for V6B $(n=18)$. The average number of reads per swab was $2626+/$ 1262 for V6F and $1606+/-815$ for V6B (Table 3). By the two-sided t-test, these two numbers were statistically significantly different $(p=0.020)$. The average total percent of those bacteria comprising at least $1 \%$ of the reads was $95.0+/-1.0$ for $\mathrm{V} 6 \mathrm{~F}$ and 95.6 $+/-1.2$ for V6B. These two numbers were not significantly different $(p=0.23)$. The average numbers of reads per swab were statistically significantly lower in Order as compared to Class (V6F, $\mathrm{p}=0.044$; V6B, $\mathrm{p}<0.00001)$. The average total percentage of reads identifying bacteria supported by, at least, $1 \%$ of the reads was also statistically significantly lower in Order as compared to Class (V6F and V6B, $\mathrm{p}<0.00001$ ). Obviously, one of the reasons for these results was that 
there are multiple Orders in each Class, thus distributing the reads into more categories.

The sums of the V6 skin microbe Order identifications are presented in Table 5B. All 26 swabs contained at least $1 \%$ of the reads as Actinobacteridae and Enterobacteriales. Bacillales were present on all Front swabs and on all but one (94\%) of the Back swabs. Alteromonadales, Burkholderiales and Chromatiales appeared on a majority of swabs. There were many other bacterial Orders that appeared on fewer swabs (Table 3 and 5B). The Order Enterobacteriales (a member of the of Gammaproteobacteria Class) was supported by the most reads for 15 of 26 swabs (58\%, Table 5B). For the remaining eleven swabs, Actinobacteridae (a member of the Actinobacteria Class) was supported by the most reads on eight swabs $(31 \%)$. Bacillales (a member of the Bacilli Class) was supported by the most reads on three swabs $(12 \%)$.

The average percent of reads supporting the three most abundant bacterial Orders (Actinobacteridae, Bacillales, Enterobacteriales) is shown in Table 5B. The average percent $(41.5+/-19.3 \% ; \mathrm{n}=8)$ of Enterobacteriales on the Front swabs was not statistically significantly different from the average percent $(43.8+/$ $13.6 \% ; n=18$ ) of Enterobacteriales on the Back swabs ( $p$ $=0.73$ ). Further comparisons were compromised by the fact that there was only one Front swab from a female.

Nevertheless, none of the comparisons that could be made yielded a statistically significantly difference.

Unfortunately, for V3, only 17 swabs produced data (Table 2B). The data identify bacterial Class only. There are three Front plus Back pairs (swabs 32, 36 and 40), six solo Front swabs and five solo Back swabs (Table 2B).

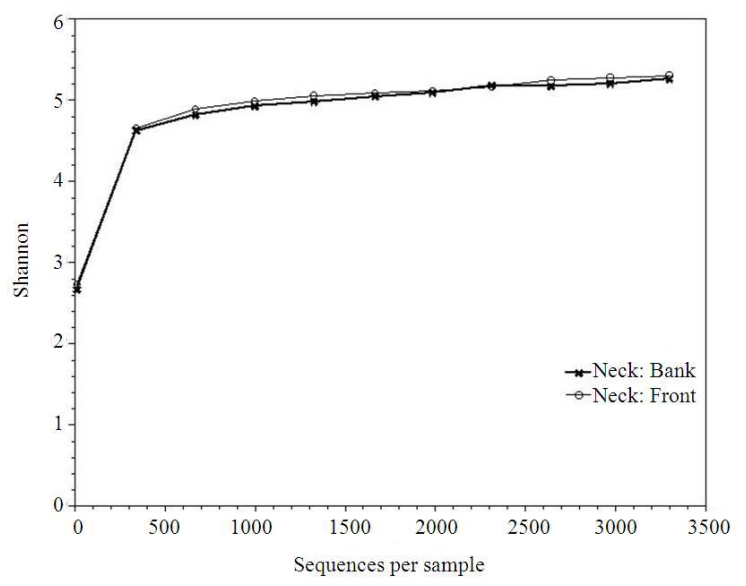

Fig. 3: Shannon Diversity Index of the V6 data from the Front of the base of the neck and the Back of the base of the neck
The most important point is that the V3 data identified the same nine Classes of bacteria already seen from the V6 data. All swabs contained, at least, $1 \%$ of the V3 reads as Actinobacteria, Bacilli and Gammaproteobacteria. The majority of the swabs contained, at least, $1 \%$ of the $\mathrm{V} 3$ reads as Betaproteobacteria and Flavobacteria. A few swabs contained Alphaproteobacteria, Clostridia, Cyanobacteria, or Sphingobacteria, at least at the $1 \%$ level (Table 2B). In general, the percent of reads supporting the presence of each bacterium was different for V3 and V6. This result was expected. The number of bases comprising V3 and V6 are quite different. It has already been established that the length of the amplicon strongly influences the number of reads (Huber et al., 2009).

\section{CONCLUSION}

Following published classifications (Grice and Segre, 2011; Kong, 2011), the two human skin sites studied herein are "dry" sites. The previously studied location physically closest to the Front of the base of the neck is the manubrium (upper chest), where the microbiome is composed, nearly entirely, of Actinobacteria (Costello et al., 2009; Grice et al., 2008; Grice et al., 2009). Actinobacteria comprise less than $20 \%$, on average, of the microbiome on the Front of the base of the neck. Despite the geographical closeness, the two microbiomes are distinct. The physically closest studied location to the Back of the base of the neck (nape) is the occiput (back scalp). The occiput microbiome is composed principally of Firmicutes (majority bacteria) and Actinobacteria (minority bacteria) (Costello et al., 2009; Grice et al., 2008; 2009). The Firmicutes are principally Staphylococcaceae (nearly half the total) and Proteobacteria. The nape microbiome is composed of Firmicutes (principally Gammaproteobacteria) with some Actinobacteria. These comparisons again make the point that niches separated by a small physical distance may, nevertheless, harbor distinct microbiomes.

\section{ACKNOWLEDGEMENT}

This study was supported by Public Health Service grant PO1 HG000205 from the National Human Genome Research Institute.

Author contributions: R.W.H. designed the experiments and wrote this manuscript. R.W.H. and M.F. amplified and gel-purified the V6 and V3 DNAs. F.B. performed the pyrosequencing. C.P. and C.W. 
informatically processed the reads. C.P. undertook the QIIME and UniFrac analyses of the data. R.W.D. provided the intellectual, physical and financial milieu for these experiments.

Author conflicts of interest: The authors state that they have no conflicts of interest.

\section{REFERENCES}

Caporaso, J.G., J. Kucynski, J. Stombaugh, K. Bittner and F.D. Bushman et al., 2010. QIIME allows analysis of high-throughput community sequencing data. Nat. Methods, 7: 335-336. DOI: 10.1038/nmeth.f.303

Cole, J.R., Q. Wang, E. Cardenas, J. Fish and B. Chai et al., 2009. The ribosomal database project: Improved alignments and new tools for rRNA analysis. Nucleic Acids Res., 37: D141-D145. DOI: $10.1093 / \mathrm{nar} / \mathrm{gkn} 879$

Costello, E.K., C.L. Lauber, M. Hamady, N. Fierer and J.I. Gordon et al., 2009. Bacterial community variation in human body habitats across space and time. Science, 326: 1694-1697. DOI: 10.1126/science. 1177486

Dethlefsen, L., S. Huse, M.L. Sogin and D.A. Relman, 2008. The pervasive effects of an antibiotic on the human Gut Microbiota, as Revealed by Deep 16S rRNA Sequencing. PLoS Biol., 6: e280-e280. DOI: 10.1371/journal.pbio.0060280

Fierer, N., M. Hamady, C.L. Lauber and R. Knight, 2008. The influence of sex, handedness, and washing on the diversity of hand surface bacteria. Proc. Natl. Acad. Sci. USA., 105: 17994-17999. PMID: 19004758

Grice, E.A. and J.A. Segre, 2011. The skin microbiome. Nat. Rev. Microbiol., 9: 244-253. DOI: 10.1073/pnas.0807920105
Grice, E.A., H.H. Kong, G. Renaud and A.C. Young, 2008. A Diversity Profile of the human skin microbiota. Genome Res., 18: 1043-1050. DOI: 10.1101/gr.075549.107

Grice, E.A., H.H. Kong, S. Conlan, C.B. Deming and J. Davis et al., 2009. Topographical and temporal diversity of the human skin microbiome. Science, 324: 1190-1192.

Huber, J.A., H.G. Morrison, S.M. Huse, P.R. Neal and M.L. Sogin et al., 2009. Effect of PCR amplicon size on assessments of clone library microbial diversity and community structure. Environ. Microbiol., 11: 1292-1302. DOI: 10.1111/j.14622920.2008.01857.x

Huse, S.M., L. Dethlefsen, J.A. Huber, D.B.M. Welch and D.A. Relman et al., 2008. Exploring microbial diversity and taxonomy using SSU rRNA Hypervariable Tag Sequencing. PLoS Genet., 4: e1000255. DOI: 10.1371/journal.pgen.1000255

Hyman, R.W., M. Fukushima, L. Diamond, J. Kumm and L.C. Giudice et al., 2005. Microbes on the human vaginal epithelium. Proc. Natl. Acad. Sci. USA., 102 : 7952-7957. DOI: 10.1073/pnas.0503236102

Kong, H.H., 2011. Skin microbiome: genomics-based insights into the diversity and role of skin microbes. Trends Mol. Med., 17: 320-8. DOI: 10.1016/j.molmed.2011.01.013

Lozupone, C., M.E. Lladser, D. Knights, J. Stombaugh and R. Knight, 2011. UniFrac: An effective distance metric for microbial community comparison. I.S.M.E. J., 5: 169-172. DOI: 10.1038/ismej.2010.133

Percival, S.L., C. Emanuel, K.F. Cutting and D.W. Williams, 2011. Microbiology of the skin and the role of biofilms in infection. J. Int. Wound., DOI: 10.1111/j.1742-481X.2011.00836.x 